\section{Giving feedback to medical students and trainees: rules and realities}

\author{
John Launer
}

One of the commonest requests that medical educators get from clinical colleagues is to run training sessions on how to give feedback to students and trainees. Personally, I have a mixed reaction when I receive an invitation to do this. It is always good to know that clinicians are taking their teaching role seriously. At the same time, the requests often seem to be based on a naïve assumption that the skill of giving feedback to trainees can be mastered just by learning some simple educational techniques, rather than being developed as part of an ethos of trust, respect and mutual challenge. To improve the quality of feedback, you really need to address both.

Guidance from the literature on giving feedback is fairly consistent. ${ }^{1}$ The purpose of feedback is to promote self-regulation in trainees, through helping them to recognise any discrepancies between what they are doing and what they ought to do. ${ }^{2}$ There are various sets of rules for giving feedback. The best-known are "Pendleton's rules", named after the psychologist who helped to formulate them. ${ }^{3}$ According to these rules, feedback should always follow certain fixed stages: first, the learner and then the teacher should state what was done well; next, the learner and then the teacher should say what could have been done differently; and finally the two of them agree on a joint action plan for improvement. These rules have the merit of emphasising that the learner should always speak first. However, they have come in for some criticism because of their rigid and formulaic nature. They have also been caricatured as a "kick-kiss-kick" method (not to mention ruder descriptions). Other sets of rules are somewhat more sophisticated in this respect, and are now more commonly taught. One of these, the "SHARP 5-step feedback tool", appears in Box $1 .^{4}$ It has been designed for use in simulation laboratories, but is applicable to clinical work as well.

In the hurly-burly of the hospital ward or consulting room, it can be hard to

Correspondence to Dr John Launer, Professional Development Department, Health Education England, Stewart House, 32 Russell Square, London WC1B 5DN, UK: john.launer@nwl.hee.nhs.uk

\section{Box 1: SHARP 5-step feedback tool}

- Set learning objectives beforehand: What would you like to get out of this case?

How did it go?: What went well? Why?

- Address concerns: What did not go so well? Why?

- Review learning points: Were your learning objectives met for this case? What did you learn about your clinical. technical/ and teamwork skills?

- Plan ahead: What actions can you take to improve your future practice?

remember, let alone apply, even a five-step approach. Learning there often happens opportunistically and the teaching has to be rapid. In these circumstances, it is more useful for teachers to hold on to some basic conversational principles instead. These include the guidance that feedback should be based on observation; be nonjudgemental and specific; focus on behaviours; elicit thoughts and feelings; and include suggestions for improvement For example, a statement like "you didn't seem very sympathetic" is far less helpful than saying: "I noticed the patient had tears in her eyes, and I wondered whether you saw them and considered saying anything in response." This kind of careful, respectful approach has been validated by research..$^{5}$

\section{FEEDBACK IN CONTEXT}

Educational conversations do not happen in the abstract. They occur between real people with their own personalities, strengths and weaknesses. Some teachers are assertive, while others can be timid and avoidant of challenge, particularly if they fear upsetting the learner. ${ }^{6}$ Trainees may be receptive to criticism, but alternatively they can be unaware of their failings or resistant to correction. Interactions sometimes call for more sensitivity, and more recalibration from moment to moment, than any of the standard guidance suggests. In some ways, the skills needed to give feedback are similar to the ones that doctors learn for imparting information to patients, or for breaking bad news to them. Giving negative feedback requires the same kind of careful preparation in terms of timing, setting and judicious choice of words.

It also makes a difference if the teaching relationship is trusting and long-term. It is certainly easier for trainees to accept constructive criticism from someone who has habituated them to questioning and praise over time. As one writer has put it: "Feedback must be considered as a supportive, sequential process, rather than a series of unrelated events." ${ }^{7}$ Role modelling is crucial. $^{8}$ If senior doctors themselves accept challenge, even from their juniors, and can openly admit their errors and correct these, everyone around them will accept this as a natural part of professionalism. The literature on feedback also draws attention to the so-called "hidden" curriculum. 9 This includes everyday behaviour in the workplace, and the values and implicit in this. Where trainees feel treated as an essential part of the team, for example, and are closely involved in discussions and decisionmaking, they are more likely to reflect on their learning than if they feel undervalued or peripheral.

As trainees progress further in their careers, their education will need to focus less on knowledge and skills, and more on developing professional judgement in situations of complexity and uncertainty. In such situations, rules and principles are gradually less useful, and trainees need to be drawn instead into a mature, equal dialogue. ${ }^{10}$ By this stage, giving feedback is very different from taking a conventional position of authority, where one person guides another towards "the right thing to do." What is needed instead is a shared attitude of curiosity. The teacher's expertise resides in an ability to question all certainties, including their own, and to conduct an open dialogue involving patients, learners and colleagues equally. The task for the trainee is to participate in this fully. In the long run, it may be more useful to judge the quality and effectiveness of feedback in medical training by whether or not it helps to develop this attitude in both the clinical teacher and the trainee.

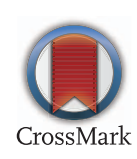

To cite Launer J. Postgrad Med J 2016;92:627-628.

Postgrad Med J 2016;92:627-628.

doi:10.1136/postgradmedj-2016-134494 


\section{On reflection}

\section{REFERENCES}

1 Wood D. Formative assessment. In: Swanwick T, ed Understanding Medical Education: Evidence, Theory and Practice, $2^{\text {nd }}$ edition. Chichester, UK: Wiley-Blackwell, 2014.

2 Nicol DJ, Macfarlane-Dick D. Formative assessment and self-regulated learning: a model and seven principles of good feedback practice. Studies in Higher Education 2006;31:199-218.

3 Pendleton D, Schofield T, Tate $P$, et al. The Consultation: An Approach to Learning and Teaching. Oxford: Oxford University Press, 1983.
4 Imperial College, London. The London Handbook for Debriefing: Enhancing Debriefing in Clinical and Simulated Settings. London: Imperial College, 2010. https://workspace.imperial.ac.uk/ref/Public/ UoA\%2001\%20-\%20Clinical\%20Medicine/ Iw2222ic_debrief_book_a5.pdf (accessed 27 August 2016).

5 Hewson MG, Little ML. Giving feedback in medical education: verification of recommended techniques. J Gen Int Med 1998;13:111-6.

6 Hesketh EA, Laidlaw GM. Developing the teaching instinct. 1: Feedback. Med Teacher 2002;24:245-8.
7 Archer JC. State of the science in health professional education: effective feedback. Med Ed 2010;44:101-8.

8 Cruess SR, Cruess RL, Steinert Y. Role modelling: making the most of a powerful teaching strategy. BMJ 2008;336:718-21.

9 Hafferty F, Franks R. The hidden curriculum, ethics, teaching and the structure of medical education. Acad Med 1994;69:861-71.

10 Ahluwalia S, Launer J. Training for complexity and professional judgement. Beyond communication skills plus evidence. Ed Primary Care 2012;23: 317-9. 